\title{
Ischaemic brain lesions diagnosed at birth in preterm infants: clinical events and developmental outcome
}

\author{
S K Sinha, S W D'Souza, E Rivlin, M L Chiswick
}

\begin{abstract}
In 232 newborn babies of $<32$ weeks' gestational age ultrasound brain scans were carried out shortly after birth, daily for the first week of life, and at least twice weekly thereafter. Periventricular echogenicity associated with or progressing to periventricular leucomalacia (ischaemic brain lesions) was present in nine babies within two hours of birth (early onset); 30 other babies subsequently developed similar lesions (late onset). Babies with early onset lesions were more likely to have a history of intrauterine growth retardation and to have recurrent apnoea in the first few hours after birth. By contrast, late onset lesions were associated with hyaline membrane disease. In later childhood four of six survivors with early onset periventricular leucomalacia, and seven of 14 survivors with late onset periventricular leucomalacia, had various disabilities including spastic diplegia, impaired vision, squints, sensorineural hearing loss, and developmental delay. In a third of the children with disabilities ischaemic brain lesions were noted within two hours of birth, raising the possibility that some of this damage had taken place before or during birth.
\end{abstract}

Certain clinical events that occur before or during birth may lead to ischaemic brain lesions and periventricular haemorrhage in newborn babies. ${ }^{2}$ These include maternal antepartum haemorrhage, and perinatal hypoxia, hypercapnia, and acidosis in the baby. As the quality of ultrasound imaging has improved with the use of high resolution probes $(7.5 \mathrm{MHz})$ areas of increased echogenicity consistent with brain ischaemia can be recognised with greater accuracy, and their progress to the development of cystic areas (periventricular leucomalacia) has been described. ${ }^{3}$ Periventricular leucomalacia seems to occur more often in newborn babies weighing $<1000 \mathrm{~g}$ and had been correlated with intrauterine infections, and placental vascular anastomosis in twins. ${ }^{4}$ In a previous study we suggested that a reduction in systemic blood pressure associated with birth asphyxia, antepartum haemorrhage, recurrent apnoea, and septicaemia is responsible for the ischaemic brain lesions. ${ }^{5}$

In the present study we report various clinical events in babies in whom evidence of ischaemic brain lesions was present on the first ultrasound scan. We compared these findings with those in babies who subsequently developed similar brain lesions in our special care baby unit. Both groups of babies were followed up after leaving hospital and their developmental outcome assessed.

\section{Patients and methods}

Ultrasound brain scans were carried out in an unselected group of 232 newborn babies of $<32$ weeks' gestational age born at this hospital, from January 1984 onwards. The scans were carried out shortly after birth, daily for the first week of life, and at least twice weekly thereafter during their stay in the special care baby unit. A Technicare mechanical sector scanner with a $7 \cdot 5$ $\mathrm{MHz}$ probe was used and during the scanning special attention was given to the presence of areas of increased echogenicity consistent with ischaemic brain lesions (periventricular leucomalacia), periventricular haemorrhage, and ventricle size as previously described. ${ }^{3}$ A record of each brain scan was kept on videotape. The accuracy of our findings on ultrasonography compared with those at necropsy was confirmed in a total of 53 babies who died during the neonatal period. The consistency was $85-90 \%$, which is comparable with previous reports. ${ }^{6}$ Clinical information was recorded prospectively for each baby.

\section{FOLLOW UP}

Babies with a history of periventricular leucomalacia were seen regularly in the outpatient clinic at a hospital near their place of residence, and information about their clinical progress was made available to us. They were also seen at this hospital at 18 to 48 months of age, when each child had a general medical and detailed neurological assessment according to our established protocol. ${ }^{7}$ Development was assessed subjectively according to Illingworth, ${ }^{8}$ at outpatient visits, and objectively by the Griffiths's scales of mental development in our department of child psychology for evidence of developmental delay (developmental quotient $<80$ ). ${ }^{9}$ If a squint or visual impairment was suspected the child was referred to an ophthalmologist. Those children with hearing impairments were referred for detailed audiological testing.

\section{STATISTICAL ANALYSIS}

Mean values were compared using Student's $t$ test. When comparing differences in propor- 
tions, Fisher's exact test or the $\chi^{2}$ test were used, as appropriate.

\section{Results}

'EARLY ONSET' AND 'LATE ONSET' ISCHAEMIC BRAIN LESIONS (PERIVENTRICULAR LEUCOMALACIA) Periventricular areas of increased echogenicity consistent with ischaemic brain lesions were diagnosed in $39(17 \%)$ of 232 babies from the videotape recordings. ${ }^{5}$ These areas of increased echogenicity were associated with or progressed to multiple periventricular cysts (periventricular leucomalacia). ${ }^{3}$ The time of ultrasound diagnosis of such ischaemic brain lesions varied between one and 70 days. In nine (23\%) of 39 babies, lesions consistent with brain ischaemia were present on the initial scan carried out within two hours of birth (range 30 minutes to 2 hours; median 30 minutes). These nine babies were in the early onset group of ischaemic brain lesions; six survived and were followed up after they had left hospital. A total of 30 babies (77\%) developed lesions consistent with brain ischaemia between 4 and 70 days postnatally (median 7 days); 15 babies who survived were followed up.

\section{ANTENATAL AND BIRTH HISTORY}

Table 1 shows the antenatal and birth history in babies with early onset and late onset ischaemic brain lesions. The only significant difference between the two groups was a higher proportion of babies with a history of intrauterine growth retardation among those with early onset lesions. These babies were also 'small for dates', as their birth weights were below the 3rd centile for gestational age. ${ }^{10}$ Mothers who had vaginal bleeding at any time during the second or third trimesters of pregnancy, or a retroplacental clot on examination of the placenta, were deemed to have had an antepartum haemorrhage (table 1). The indications for caesarean section (table 1) in the early onset group with brain ischaemia were late fetal heart rate decelerations in the cardiotocogram recordings $(n=3)$, and intrauterine growth retardation $(n=1)$. In the late onset group, the caesarean sections were carried out for pre-eclamptic toxaemia $(n=5)$, antepartum

Table 1 Antenatal and birth history

\begin{tabular}{|c|c|c|}
\hline & \multicolumn{2}{|c|}{ Ischaemic brain lesions } \\
\hline & $\begin{array}{l}\text { Early onset } \\
(n=9)\end{array}$ & $\begin{array}{l}\text { Late onset } \\
(n=30)\end{array}$ \\
\hline \multicolumn{3}{|l|}{ Antenatal conditions: } \\
\hline $\begin{array}{l}\text { Pre-eclamptic toxaemia } \\
\text { Prolonged rupture of membranes }\end{array}$ & 1 & 8 \\
\hline ( $>24$ hours) & 4 & 5 \\
\hline Antepartum haemorrhage & 5 & 12 \\
\hline Late fetal heart rate decelerations & 3 & 7 \\
\hline Intrauterine growth retardation & 5 & $1^{* *}$ \\
\hline \multicolumn{3}{|l|}{ Mode of delivery: } \\
\hline $\begin{array}{l}\text { Vaginal: } \\
\text { Cephalic }\end{array}$ & & \\
\hline $\begin{array}{l}\text { Lephallc } \\
\text { Breech }\end{array}$ & $\begin{array}{l}5 \\
0\end{array}$ & $\begin{array}{l}8 \\
2\end{array}$ \\
\hline Forceps & 0 & 1 \\
\hline \multicolumn{3}{|l|}{ Caesarean section: } \\
\hline In labour & 3 & 10 \\
\hline Before labour & 2 & 9 \\
\hline \multicolumn{3}{|l|}{ Birth: } \\
\hline \multicolumn{3}{|l|}{ Birth asphyxia-Apgar score: } \\
\hline$<5$ At 1 minute & 2 & 16 \\
\hline Mean (SD) birth weight (g) & $1093(496)$ & $1237(329)$ \\
\hline Mean (SD) gestational age (weeks) & $28 \cdot 8(1 \cdot 8)$ & $28 \cdot 4(2 \cdot 6)$ \\
\hline Small for dates & 5 & $1^{* *}$ \\
\hline
\end{tabular}

haemorrhage $(n=3)$, prolonged rupture of membranes $(n=2)$, breech presentation $(n=1)$, intrauterine growth retardation $(n=1)$, and late fetal heart rate decelerations $(n=7)$.

\section{NEONATAL EVENTS}

Various neonatal events that occurred in the two groups of babies are shown in table 2 . There were significant differences in the frequency of hyaline membrane disease and of recurrent apnoea. A higher proportion of babies with late onset ischaemic brain lesions had hyaline membrane disease. By contrast, a greater proportion of those with early onset brain lesions had recurrent apnoea, which was severe enough for the babies to require respiratory support by mechanical ventilation. The cessation of respiration during apnoea was associated with bradycardia, the heart rate slowing typically to less than 100 beats/minute. Brain haemorrhage was associated with the ischaemic lesions in similar proportions of babies in the two groups (table 2).

\section{DEVELOPMENTAL OUTCOME}

In later childhood, four of the six surviving babies with early onset ischaemic brain lesions had disabilities-spastic diplegia, impaired vision, sensorineural hearing loss, squints, and developmental delay (table 3). None of the four

Table 2 Neonatal events

\begin{tabular}{|c|c|c|}
\hline & \multicolumn{2}{|c|}{ Ischaemic brain lesions } \\
\hline & $\begin{array}{l}\text { Early onset } \\
(n=9)\end{array}$ & $\begin{array}{l}\text { Late onset } \\
(n=30)\end{array}$ \\
\hline \multicolumn{3}{|l|}{ Neonatal conditions: } \\
\hline Hyaline membrane disease & 3 & $22^{*}$ \\
\hline Recurrent apnoea & 6 & $3^{* *}$ \\
\hline \\
\hline \multirow{2}{*}{\multicolumn{3}{|c|}{$\begin{array}{l}\text { Patent ductus arteriosus (treated } \\
\text { with indomethacin) }\end{array}$}} \\
\hline & 3 & 9 \\
\hline \multicolumn{3}{|l|}{ Septicaemia (positive blood } \\
\hline Pneumothorax & 2 & 12 \\
\hline Muscle paralysis (pancuronium) & 2 & 15 \\
\hline \multicolumn{3}{|c|}{ Brain haemorrhage (ultrasound scans): } \\
\hline \multirow{2}{*}{$\begin{array}{l}\text { Subependymal haemorrhage } \\
\text { Intraventricular haemorrhage } \\
\text { only }\end{array}$} & 2 & 3 \\
\hline & 4 & 15 \\
\hline $\begin{array}{l}\text { Intraventricular haemorrhage } \\
\text { with parenchymal extension }\end{array}$ & 0 & 4 \\
\hline \multicolumn{3}{|c|}{ Blood gas analysis (first four days of birth): } \\
\hline \multirow{3}{*}{$\begin{array}{l}\text { Arterial oxygen pressure }<6.7 \mathrm{~kJ} \\
\text { in }>60 \% \text { oxygen } \\
\text { Arterial carbon dioxide pressure } \\
>8.0 \mathrm{kPa} \\
\text { pH }<7.2 \text { with base deficit }>10.0 \\
\text { Death }\end{array}$} & 6 & 26 \\
\hline & $\begin{array}{l}1 \\
1\end{array}$ & $\begin{array}{l}15 \\
24\end{array}$ \\
\hline & 3 & 15 \\
\hline \multicolumn{3}{|c|}{${ }^{*} \mathrm{p}<0.05,{ }^{* *} \mathrm{p}<0.005$, Fisher's exact test. } \\
\hline \multicolumn{3}{|c|}{$\begin{array}{l}\text { Table } 3 \text { Outcome in later childhood ( } 18 \text { to } 48 \text { months) in } \\
\text { survivors with ischaemic brain lesions }\end{array}$} \\
\hline \multirow[t]{2}{*}{ Clinical findings } & \multicolumn{2}{|c|}{ Ischaemic brain lesions } \\
\hline & $\begin{array}{l}\text { Early onset } \\
(n=6)\end{array}$ & $\begin{array}{l}\text { Late onset } \\
(n=14)\end{array}$ \\
\hline Spastic diplegia & 3 & 5 \\
\hline $\begin{array}{l}\text { Impaired vision } \\
\text { Squints }\end{array}$ & $\begin{array}{l}1 \\
3\end{array}$ & $\begin{array}{l}3 \\
4\end{array}$ \\
\hline $\begin{array}{l}\text { Squints } \\
\text { Sensorineural deafness }\end{array}$ & 1 & i \\
\hline Developmental delay & 4 & 3 \\
\hline \multirow{2}{*}{$\begin{array}{l}\text { No of children with any one of } \\
\text { above disabilities } \\
\text { No of children with no detectable } \\
\text { abnormality }\end{array}$} & 4 & 7 \\
\hline & 2 & 7 \\
\hline
\end{tabular}


children with disabilities had a history of late decelerations of fetal heart rate on cardiotocographic tracings, or of birth asphyxia (Apgar score $<5$ at 1 minute). One of the remaining two children with no disability had a history of birth asphyxia. In the 15 babies with late onset ischaemic brain lesions, one died during the first three months after leaving hospital of sudden infant death syndrome. Of the remaining 14 children, seven had disabilities similar to those in the 'early onset' group. Five of the seven children with disabilities had histories of late fetal heart rate decelerations or birth asphyxia. In the remaining seven children with no disabilities, two had similar histories of birth asphyxia. In these 11 children with disabilities in later childhood, ischaemic lesions of early onset had contributed to brain damage in a third of the total number of cases.

\section{Discussion}

The risks of periventricular leucomalacia of early onset seems to be increased in babies with a history of intrauterine growth retardation. Periventricular deucomalacia is caused by infarction in areas of the brain that are especially vulnerable to reduced perfusion, including the 'watershed' areas distributed between the 'ventriculofugal' and 'ventriculopetal' branches of cerebral blood vessels. ${ }^{11}$ It is also possible that these areas become damaged when hypoxic episodes give rise to cerebral oedema, as an increase in intracranial pressure as a result of oedema may reduce cerebral perfusion. Intrauterine growth retardation has been associated with certain conditions including impaired uteroplacental blood flow ${ }^{12}$ and a reduction in cardiac glycogen reserves. ${ }^{13}$ The former might be expected to increase the likelihood of fetal hypoxia, while the latter may lead to a progressive reduction in cardiac output when stressed by hypoxia and thus limit the ability of the growth retarded fetus to maintain its blood pressure. A similar sequence of events may have resulted in a reduction in cerebral blood flow in our infants with a periventricular leucomalacia of early onset.

We cannot be precise about the timing of ischaemic brain lesions diagnosed soon after birth from the obstetric information available. In some babies who had no history of late fetal heart rate deceleration, or low Apgar scores $(<5$ at 5 minutes) associated with the ultrasound appearance of brain ischaemia, the brain damage may have taken place before birth. In others who did have histories of fetal hypoxia or birth asphyxia, these conditions may have predisposed to ischaemic brain lesions that progressed postnatally. It is possible that blood pressure recordings carried out shortly after birth (unpublished observations) may improve the recognition of babies who are poorly perfused. Treatment aimed at the maintenance of blood pressure, which includes giving plasma and inotropic drugs, may improve cerebral blood flow and thus lead to a decrease in the incidence of periventricular leucomalacia.

Recurrent apnoeic episodes and bradycardia may have a role in exacerbating hypoxic- ischaemic brain damage in preterm babies. ${ }^{14}$ Such apnoeic episodes may lead to a reduction in systemic blood pressure, and a reduction in cerebral blood flow, depending on the severity of the decline in heart rate (bradycardia). ${ }^{14}$ Our ultrasonographic findings suggest that the ischaemic insult to the brain in the early onset group had preceded the apnoeic episodes. In this setting, repeated episodes of apnoea and bradycardia may potentiate the progress of ischaemic injury to periventricular leucomalacia in the arterial border zones that are most susceptible to damage. Ventilating such babies could have the desired effect of preventing bradycardia associated with apnoeic episodes. The subsequent progress of these babies may, however, be complicated by periventricular haemorrhage from blood vessels that had previously been damaged by ischaemia.

Ischaemic brain damage of late onset seems to have a different aetiology, as we found an association with hyaline membrane disease in babies who were appropriately grown for their gestational ages. The relationship between hyaline membrane disease and periventricular haemorrhage is well known. ${ }^{11}$ In similar babies, serial brain scans carried out by us showed ultrasound appearances consistent with periventricular leucomalacia after the development of periventricular haemorrhage. ${ }^{5}$ Though the reasons for this are not clear it may be that a reduction in carbon dioxide pressure during mechanical ventilation, ${ }^{2}$ a fall in systemic blood pressure from blood loss caused by the haemorrhage, or an intracerebral haematoma ${ }^{15}$ may have contributed to a reduction in regional cerebral blood flow and ischaemic brain damage.

By only including babies who developed cystic brain lesions (periventricular leucomalacia) in our study, we are confident in the selection of those with ischaemic brain damage. Unlike periventricular haemorrhage, which does not usually occur after the first seven days of life, periventricular leucomalacia in our study occurred over a wider time period. This, together with the progression of areas of increased echogenicity in the periventricular region to cystic lesions in ultrasound brain scans, is consistent with previous reports. ${ }^{31617} \mathrm{We}$ are aware that having excluded babies in whom areas of echogenicity did not progress to cystic lesions it is possible that some babies with ischaemic brain damage were not considered in our study, as cystic lesions less than $3 \mathrm{~mm}$ in size are not likely to be recognised by the present scanning method. ${ }^{316}$ In cases similarly selected we have previously suggested that the high neonatal mortality rate and the development of ventricular enlargement as a result of brain atrophy are the immediate consequences of ischaemic brain damage. In the present study the late complications of such damage appear to be cerebral palsy, sensorineural hearing loss, and visual impairment.

In a third of the babies in this study with disabilities (including cerebral palsy in later childhood) the ischaemic brain damage may have already taken place by the time of birth. This has implications for our understanding of mechanisms underlying abnormal development 
in preterm babies and emphasises the greater risks attached to intrauterine growth retardation. Obstetric management directed towards optimal timing and mode of delivery should seek to prevent the early onset of periventricular leucomalacia.

Financial support from the North Western Regional Health Authority is gratefully acknowledged.

1 Weindling AM, Wilkinson AR, Cook J, Calvert SA, Fok T-F, Rochefort MJ. Perinatal events which precede periventricular haemorrhage and leucomalacia in the newborn. Br $\mathcal{F}$ Obstet Gynaecol 1985;92:1218-25.

2 Calvert SA, Hoskins EM, Fong KW, Forsyth SC. Etiologica factors associated with the development of periventricular leucomalacia. Acta Paediatr Scand 1987;76:254-9.

3 Dubowitz LMS, Bydder GM, Mushin J. Developmental sequence of periventricular leukomalacia. Arch Dis Child 1985;60:349-55.

4 Bejar R, Wozniak P, Allard M, et al. Antenatal origin of neurologic damage in newborn infants 1 . Preterm infants. neurologic damage in newborn infants 1.

5 Sinha SK, Davies JM, Sims DG, Chiswick ML. Relation between periventricular haemorrhage and ischaemic brain lesions diagnosed by ultrasound in preterm infants. Lancet 1985;ii: $1154-5$.

6 Trounce JQ, Fagan D, Levene MI. Intraventricular haemor- rhage and periventricular leucomalacia: ultrasound and autopsy correlation. Arch Dis Child 1986;61:1203-7. 7 Marlow N, D'Souza SW, Chiswick ML. NeurodevelopmenMed F 1987;294:1582-6.

8 Illingworth RS. The normal child. London: Churchill Livingstone, 1977.

9 Griffiths R. The abilities of babies: a study of mental measurement. Amersham: Association for Research in Infants and Child Development, 1976

10 Keen DV, Pearse RG. Birthweight between 14 and 42 weeks' gestation. Arch Dis Child 1985;60:44-6.

11 Pape KE, Wiglesworth JS. Haemorrhage, ischaemia and the perinatal brain. Clinics in Developmental Medicine Nos 69/ perinatal brain. Clinics in Developmental Medicine Nos 69/
70. Spastics International Medical Publications. London: 70. Spastics Internatio

12 Campbell S, Diaz-Recasens J, Griffin D, et al. New Doppler technique for assessing utero-placental blood flow. Lancet 1983;i:675-9.

13 Adlard BPF, D'Souza SW, Dobbing J. Effect of growth retardation and asphyxia on brain electrolytes and on glycolysis in developing rats. Pediatr Res 1973;7:494-9.

14 Perlman JM, Volpe JJ. Episodes of apnoea and bradycardia in the preterm newborn: impact on cerebral circulation. Pediatrics 1985;76:333-8.

15 Volpe JJ, Herscovitch P, Perlmann JM, Raichle ME. Positron emission tomography in the newborn: extensive impairment of regional cerebral blood flow with intraventricular haemorrhage and haemorrhagic intracerebral involvement. Pediatrics 1983;72:589-601.

16 Rushton DI, Preston PR, Durbin GM. Structure and evolution of echo dense lesion in the neonatal brain: a combined tion of echo dense lesion in the neonatal brain: a combined
ultrasound and necropsy study. Arch Dis Child 1985;60: ultrasoun

17 De Vries LS, Regev R, Dubowitz LMS. Late onset cystic leucomalacia. Arch Dis Child 1986;61:298-9. 